\title{
Effect of Structured In-service Education on Knowledge level among Nurses Working in Surgical Units in Private Tertiary Hospital Islamabad, Pakistan
}

\author{
Article by Nuzhat Sultana \\ Ph.D Nursing, Texila American University, Pakistan \\ Director Nursing Education Services, Shifa International Hospital Islamabad, Pakistan \\ Email: nuzhatsultana@hotmail.com
}

\begin{abstract}
Background: Colostomy care is an important nursing intervention to ensure patient and family centered care. A number of patients go through colostomy procedure annually. The assessment of nurse's knowledge of colostomy care has not been conducted before in study hospital. Therefore, it is important to assess the knowledge of nurses caring for colostomy patients.

Purpose: The purpose of this study was to determine the effect of structured in-service education on knowledge level among nurses working in male and female surgical units.

Method: Participatory Action Research (PAR) approach was selected using pre and post - test method to assess the nurse's knowledge regarding colostomy care after the approval of IRB in a tertiary hospital, Islamabad, Pakistan.

Sample: The purposive sampling technique was used to select the study participants $(n=39)$.

Finding: The study findings showed that in pre-test nearly all of the study participants ( $n=36$, 92.3\%) received the score between 0-10 (poor and average). While in post-test the majority of the study participants ( $n=34,87.18 \%)$ received the score between 21-25 (excellent). Pair t-test showed the mean score in pre-test $6.08 \pm 3.74$ and post-test mean score 22.38 \pm 5.54 , P-value $<0.05$, Paired ' $t$ ' test revealed that the nurses gained significant knowledge after the structured in-service education.

Conclusion: The study concluded that there is an intense need for nurse managers to pay attention to this special area of nursing care by developing the mechanism for nurse's in-service education on regular basis for colostomy care. Moreover, future researches are warranted to validate the findings of this study.
\end{abstract}

Keywords: Colostomy care, pre-test, post-test, nurse's knowledge, assessment, in-service education.

\section{Introduction}

Nurses play crucial role in caring short term and long-term colostomy patients and preparing them for self- care and coping with changed health status. Appropriate nurse's knowledge of managing colostomy patient is essential. Nurses are involved in holistic care of colostomy patients, preoperative care, post operative care, care of colostomy, assessing the peristalsis movements and stool characteristics, monitoring and managing complications, colostomy irrigation, optimal nutrition, patient and family education (Bhzeh, Teleb, Mahmoud, \& Soliman, 2013). According to the literature, colostomy is a surgical procedure that takes out one end of large intestine and colon is side tracked through an incision in the abdominal wall to form a stoma. A stoma is the opening in the skin where a small bag for collecting feces attached. People with temporary or long-term colostomies have pouches attached to their sides where feaces collect and can be easily disposed off (Bhzeh, et al., 2013; Burch, 2011; Krans, January 8, 2016). Colostomy is named according to the site of opening: it may be ascending, descending, transverse or sigmoid colostomy cited in (Bhzeh, et al., 2013).

A number of patients undergo colostomy procedure every year to treat and reduce patient's pain and discomfort. On the other hand, this procedure causes stress and agony for patients, as a result of skin irritation $76 \%$, pouch leakage $62 \%$, unpleasant odor $59 \%$, discontinue of enjoyable activities 
Texila International Journal of Clinical Research

Volume 3, Issue 2, Dec 2016

54\%, and depression/anxiety 53\%, cited in (Dabirian, Yaghmaei, Rassouli, \& Tafreshi, 2011). It is estimated that about 13,000 colostomy procedures are performed annually in Canada that needs patient centered care in the hospitals (Recalla et al., 2013). Literature supports that nurses taking care of colostomy patients must be well equipped with required knowledge related to colostomy care to provide high standard care based on patient's need (Bales, 2010; Bhzeh, et al., 2013; Lebona, Jasmine, Lakshmi, \& Indira, 2016).

A study conducted in Iran reported that living with stoma affects the overall quality of life. Therefore, health care professional must be knowledgeable to cater the patients physical and psychological educational needs (Anaraki et al., 2012). Previous literature also indicated that nurses can play significant role in physical, psychological, economical, social and many other aspects of care in colostomy patients provided they are adequately updated through in-service education related to colostomy care (Sinha, Goyal, Singh, \& Rana, 2009).

A recent literature supports the importance of addressing nurses in-service educational needs related to colostomy care. A qualitative study conducted on 32 gynecologic cancer patients with colostomy in Turkey indicated that patients felt the high need for psychological support from nurses to minimize the fear, worry and anxiety and women going under colostomy were concerned about their body image, self-esteem, social activity and sexuality while in need for support from nurses (Gül, Ayhan, \& Tevfik, 2013). Literature further states that colostomy patients go-through lot of stress and feeling undignified. The stoma is usually red, inflamed, and outsized immediately after the surgery and horrible for the patient to look at for the first time. The emotional distress, along with physical problems, pain, isolation from others, and fear of death, will inevitably reduce quality of life further that may be looked after by the nurses who are better prepared with current knowledge related to colostomy care (Dabirian, et al., 2011).

Moreover, nurses play important role in patients teaching about changing colostomy bag, fear of leakage, disruption in sleep (Baldwin et al., 2009), also help patients feeling stigmatize (Smith, Loewenstein, Rozin, Sherriff, \& Ubel, 2007), helping young patients feelings embarrassed and frustrated due to their ostomy (Recalla, et al., 2013). Suicidal ideation after colostomy procedure was reported as for men 5.5\% and female $8.1 \%$ who needed nurses support (Krouse et al., 2009). Colostomy patients suffering with depression and facing multiple problems seek help from nurses (Thamilselvam, Khairuzi, \& Fadzli, 2013). A recent study conducted in Pakistan reported the lack of trained nurses in colostomy care (Zakri, Shah, Khaliq, \& Asghar, 2010). Managing colostomy patient is a complex situation, it is important that time to time nurses knowledge must be up-dated to help the patient to manage their colostomy care (Ardigo \& Amante, 2013).

A recent descriptive study conducted in Assiut University Hospital, Egypt to evaluate the knowledge and practice of 60 nurses in selected area related to colostomy care established that $82.7 \%$ nurses had satisfactory level about the definition of colostomy, 9.6\% knew the types of colostomy, $26.9 \%$ had satisfactory level of causes of colostomy, $7.7 \%$ understood the physiology of colon, $46.2 \%$ recognized anatomy of colon and $11.5 \%$ had satisfactory level of knowledge about most favorable nutrition for colostomy patients (Bhzeh, et al., 2013). Another study conducted on 189 nurses to assess nurses knowledge on pre-test and post-test reported the significant effect and enhanced knowledge and confidence on the quality and provision of care for ostomy wound management (Bales, 2010). Here colostomy patients need better-prepared nurses who can help them to cope with changed health condition.

Nursing care of colostomy is significant action to ensure quality of care (Bhzeh, et al., 2013). A recent literature review conducted by Registered Nurses' Association of Ontario supports that colostomy patients stated that the early interventions from nurses to their stoma was an marker of how they would live with their stoma (Recalla, et al., 2013). Another study suggested that nurses working with colostomy care must attained colostomy courses, seminars and workshop to enhance their knowledge and skills related to colostomy care (Thamilselvam, et al., 2013). 
Many other researches also identified the need to assess the nurse's knowledge regarding colostomy care (Ardigo \& Amante, 2013; Bhzeh, et al., 2013; Lebona, et al., 2016). A recent study conducted to assess the nurses knowledge $(n=30)$ regarding colostomy care reported that $(n=8,53 \%)$ had inadequate knowledge, $(n=6,40 \%)$ had moderately adequate knowledge and $(n=1,6.7 \%)$ had adequate knowledge. The study concluded that majority of staff nurses had inadequate knowledge regarding colostomy care (Lebona, et al., 2016).

In the study hospital, 5-6 average colostomy procedures are done every month that indicates the need to assess the nurse's existing knowledge related to colostomy care and determine the effect of structured in-service session. On literature search via scholarly article, PubMed, Wiley online library and Research Gate researcher found very few studies on the selected topic indicating the need to conduct the study on selected topic. Moreover, there is no such study conducted before at the study hospital. Therefore, current study was planned to assess the nurse's knowledge and determine the effect of structured in-service education regarding colostomy care before and after the training session.

\section{Objective of the study}

The objective of the study was to assess the knowledge of nurses related to colostomy care before and after the structured in-service education session.

\section{Research question}

To fulfill the purpose of the study following research question was formulated:

What is the difference in nurse's knowledge level before and after the structured in-service education session?

\section{Inclusion/ exclusion criteria}

All nurses working in male and female surgical units and willing to participate in the study were included in the study. Nurses on annual/sick leave and not willing to participate in the study were excluded from the study.

\section{Hypothesis}

$\mathrm{H}_{0}$ : There will be no significance difference between the pre-test and post-test knowledge score related to colostomy care among the study participants.

$\mathrm{H}_{1}$ : There will be significance difference between the pre-test and post-test knowledge score related to colostomy care among the study participants.

\section{Methodology}

\section{Study design}

The selection of research design deals with critical decision making that must be made to conduct the research study. Research approach is a systematic and objective method of discovery with empirical evidence and rigorous control. Participatory Action Research (PAR) approach was selected to conduct the study. As the nurses, training need was identified by the nurse manger surgical units and communicated to the researcher who is responsible to facilitate the nurse's trainings and their professional development across the hospital based on identified educational need of the staff through their immediate supervisor/ manager. According to Polit and Beck PAR is teamwork between researcher and study participants in identification of the problem and finding its solution. The aim of PAR is realization and action including knowledge enhancement as researcher put efforts to empower the study participants in developing and using innovative information (Polit \& Beck, 2004). 
Texila International Journal of Clinical Research

Volume 3, Issue 2, Dec 2016

\section{Independent variable}

The independent variable in this study is structured in-service educational workshop/session for nurses related to colostomy care.

\section{Dependent variable}

The dependent variable in this study is nurse's knowledge related to colostomy care.

Target population

The population of this study was all nurses working at the study hospital.

\section{Setting}

This study was conducted in Shifa International Hospital, Islamabad, Pakistan that is 500-bedded private tertiary health care facility comprised of more than 100 critical beds (medical and surgical including peads and NICU).

\section{Sampling and sample size}

Purposive sampling technique was adopted to select the study participants. All nurses $(n=50)$ working in male and female surgical units taking care of colostomy patients were invited to participate in the study. However, the actual response rate was $78 \%(n=39)$ who were available to participate in the study.

\section{Data collection tool}

Data was collected using self-developed tool based on current literature review in the form of pretest and post-test to assess/reassess the nurse's knowledge related to colostomy care. Tool consisted of two parts: Part 1: Socio-demographics characteristics of nurses; Including age, gender, academic qualification and work experience. Part 2: Included knowledge related questions; five subjective questions formulated to assess the nurse's knowledge related to colostomy care. Question no.1: posed to assess the knowledge related to definition of colostomy. Question no. 2: contained to write the types of colostomy. Question no. 3: comprised to list at least five teaching needs of colostomy patient. Question no. 4: related to food that should be recommended to colostomy patient that makes the stool soft. Question no 5: Name Supplies used for Colostomy Care and listing 3 competencies required for Colostomy Care. Each question allocated five marks as of evaluation criteria. Each item was given the score between $0-5$ according to the response of the study participants. Item wise rating indicated the various level of knowledge score from 0-5 (poor), 6-10 (average), 11-15 (good), 16-20 (very good) and 21-25 (excellent).

Two expert nurses in the field did content validity and face validity of the tool. By the end of this phase, a pilot study was carried out on $(n=4 ; 10 \%)$ of the sample to test the feasibility of the study and applicability of the tool. There was no modification made in the pre-test after the pilot study. Therefore, the study participants of the pilot study were included in the actual study as well.

\section{Ethical consideration}

The ethical aspects were considered by seeking formal approval from IRB of the study hospital before the study begins. The nurses willing to participate were included in the study along with informed written consent. The participants were assured for the confidentiality and safety of the data. Moreover, the participants were having freedom to withdraw from the study any time during the study.

\section{Data collection process}

The data was collected by researcher in last week of June 2016. Four hours structured in-service session/workshop during the morning shift (10 a.m.-2 p.m.) was conducted using the pre-test and post-test approach. After the pre-test, a planned interactive training session was delivered to impart 
the knowledge related to colostomy care among the study participants. Content was covered in detail by the responsible Nurse Manager and clinical instructor facilitate by researcher. Power point presentation session was conducted for 45 minutes including pictorials, scenarios and related videos. Power point presentation: Hand-out and recommended sites for reading were also provided to each participant during the workshop as a resource material and were given enough time to access recommended sites on internet. Study participants were also assisted to watch videos related to colostomy care followed by question answers session for 30 minutes. At the end of the workshop, post- test was conducted comprising the same questions used in pre-test. Each response was given the score according to predetermined evaluation criteria by the field experts. Each item was scored between $0-5$ according to the response of the study participants.

\section{Data analysis}

Data was entered and analyzed by using SPSS version 16. Descriptive and inferential statistics was calculated according the type of variables. Frequencies and percentages for nominal and categorical demographic variables were calculated. Mean and standard deviation was computed for participants' score in each item of knowledge related questions. Hypothesis was tested by using paired t-test. Paired t-test was applied on the mean of pre \& post-test score. Significance level was set at 0.05.

\section{Results}

\section{Demographic characteristics}

The sample constituted of nurses $(n=39)$ working in male and female surgical units. The socio demographic data of the study subjects were analyzed using descriptive statistics and were presented in terms of frequency and percentage. Majority of the participants $(n=26,66.7 \%)$ were females, aged between 21-30 Years $(n=25,64.1 \%)$. Education wise most of the participants $(n=35)$ had General Nursing 3 Years Diploma with additional one year specialty diploma in Pediatric/Psychiatric /Cardiology/ Midwifery and post RN BscN, while ( $\mathrm{n}=23,59 \%)$ had 1-10 years experience (Table 1).

Table 1. Socio demographic Variables $(n=39)$

\begin{tabular}{|l|l|l|}
\hline Variables & F & \% \\
\hline Gender & & \\
Female & 26 & 66.7 \\
Male & 13 & 33.3 \\
\hline Age & & \\
$21-30$ & 25 & 64.1 \\
$31-40$ & 8 & 20.5 \\
$41-50$ & 4 & 10.3 \\
$51-60$ & 2 & 5.1 \\
\hline Education & & \\
General Nursing 3 Years Diploma and one & 30 & 76.9 \\
year diploma ${ }^{1}$ & & \\
General Nursing plus Post RN BScN & 5 & 12.8 \\
BScN 4 Year & 4 & 10.3 \\
\hline Experience in Year & & \\
Fresh & 10 & 25.6 \\
1-10 & 23 & 59 \\
11-20 & 4 & 10.3 \\
$21 \&$ above & 2 & 5.1 \\
\hline
\end{tabular}

\footnotetext{
${ }^{1} 12$ Nurses had additional one year specialty diploma in Pediatric, Psychiatric, Cardiology \& Midwifery
} 
Texila International Journal of Clinical Research

Volume 3, Issue 2, Dec 2016

The mean score of question no. 1 in pre-test is $2.28 \pm 1.40$ and in post-test mean score 4.69 \pm 1.13 . Pvalue $<0.05$, Paired ' $t$ ' test showed that the nurses gained significant knowledge after the in-service education session. Question no. 2 the mean score of pre-test is $0.46 \pm 0.94$ and in post-test mean score 4.59 \pm 1.35 . P-value $<0.05$, Paired 't' test found the significant enhancement of knowledge in post-test. Question no. 3 the mean score in pre-test is $1.36 \pm 1.22$ and post-test mean score $4.15 \pm 1.51$, P-value < 0.05 , Paired ' $t$ ' test proved the significant increase in nurses knowledge after receiving the in-service education session. Question no. 4 the mean score of pre-test is $0.23 \pm 0.49$ and post-test mean score 4.44 \pm 1.37 . P-value $<0.05$, Paired ' $t$ ' test observed that the nurses gained significant knowledge after the intervention of in-service education session. Question no. 5 the mean score of pre-test is $1.74 \pm 1.76$ and post-test mean score $4.51 \pm 1.17$. P-value $<0.05$, Paired't' test established the significant improvement in nurses knowledge after attending the in-service session (Table 2).

Table 2. Pre-test \& Post-test Item Wise Scores

\begin{tabular}{|l|l|l|l|l|l|}
\hline \multirow{2}{*}{ Item questions } & \multicolumn{2}{|l|}{ Pre-test score } & \multicolumn{2}{l|}{ Post-test score } & $\begin{array}{l}\text { P-value } \\
\text { (Sig. 2- } \\
\text { tailed) }\end{array}$ \\
\cline { 2 - 6 } & Mean & $\begin{array}{l}\text { Std. } \\
\text { Deviation }\end{array}$ & Mean & $\begin{array}{l}\text { Std. } \\
\text { Deviation }\end{array}$ \\
\hline What is Colostomy & 2.28 & 1.40 & 4.96 & 1.13 & 0.000 \\
\hline Write Types of Colostomy & 0.46 & 0.94 & 4.59 & 1.35 & 0.000 \\
\hline $\begin{array}{l}\text { Identify at least 5 teaching } \\
\text { needs of Colostomy Patient }\end{array}$ & 1.36 & 1.22 & 4.15 & 1.51 & 0.000 \\
\hline $\begin{array}{l}\text { Name the food that soften } \\
\text { the stool }\end{array}$ & 0.23 & 0.49 & 4.44 & 1.37 & 0.000 \\
\hline $\begin{array}{l}\text { List supplies and 3 } \\
\text { competencies required for } \\
\text { Colostomy Care }\end{array}$ & 1.74 & 1.76 & 4.51 & 1.17 & 0.000 \\
\hline
\end{tabular}

Paired t-test was used to compare mean score

In overall pre-test nearly all of the study participants $(n=36,92.3 \%)$ received the score between 0 10 (poor and average); and only $(n=3,7.7 \%)$ of the participants received the score between 11-15 (good). While in post-test the majority of the study participants $(n=34,87.18 \%)$ received the score between 21-25 (excellent); while only few of the study participants $(n=3,7.7 \%)$ received the score between 16-20 (very good) and two participants who did not attempt the post-test scored zero (poor) (Table 3).

Table 3. Distribution of overall knowledge scores

\begin{tabular}{|l|l|l|}
\hline Knowledge (Score) & $\begin{array}{l}\text { Pre-test Frequency } \\
(\%)\end{array}$ & $\begin{array}{l}\text { Post-test Frequency } \\
(\%)\end{array}$ \\
\hline Poor (0-5) & $18(46.15)$ & $2(5.13)$ \\
\hline Average (6-10) & $18(46.15)$ & $0(0)$ \\
\hline Good (11-15) & $3(7.7)$ & $0(0)$ \\
\hline Very Good (16-20) & $0(0)$ & $3(7.69)$ \\
\hline Excellent (21-25) & $0(0)$ & $34(87.18)$ \\
\hline
\end{tabular}

The pair t-test knowledge score achieved by the respondents in results shows that the mean value of knowledge in pre-test is $6.08 \pm 3.74$ and at post-test $22.38 \pm 5.54$. P-value $<0.05$, Paired' $t$ ' test revealed that the nurses gained significant knowledge after the in-service education (Table 4). 
Table 4. Pair $t$ test of overall knowledge scores

\begin{tabular}{|l|l|l|l|}
\hline Pair & Mean & $\begin{array}{l}\text { Std. } \\
\text { Deviatio } \\
\mathrm{n}\end{array}$ & $\begin{array}{l}\text { P-Value (Sig. } \\
\text { 2-tailed) }\end{array}$ \\
\hline Pre-test & 6.08 & 3.74 & \\
\hline Post-test & 22.38 & 5.54 & 0.000 \\
\hline
\end{tabular}

\section{Discussion}

The study participants working in male and female surgical units $(n=39)$ were evaluated for nursing knowledge related to colostomy care. The socio demographic data of the study subjects were analyzed using descriptive statistics and were presented in terms of frequency and percentage. Majority of the participants (66.7\%) were females and 33.3\% male. Aged between 21-30 years 64.1\%; 31-40 years 20.5\%; $41-50$ years $10.3 \%$ and $51-60$ years $5.1 \%$. Education vise the most of the study participants (89.7\%) had General Nursing 3 Years Diploma with additional one year specialty diploma in Pediatric/Psychiatric/Cardiology/ Midwifery and two years post RN BscN, while $10.3 \%$ were four years $\mathrm{BscN}$ graduates. The study participant had diverse work experience between 1-10 years 59\%; $11-20$ years $10.3 \%$; 21 years \& above $5.1 \%$, while $25.6 \%$ had no work experience/just completed their basic nursing diploma.

Assessment of nurses' knowledge included five questions regarding colostomy care. The question no. 1 about the definition of colostomy in pre-test the mean score was $2.28 \pm 1.40$. These findings are similar to previous study (Bhzeh, et al., 2013). While of the same question in post-test mean score was 4.69 \pm 1.13 , P-value $<0.05$, Paired't' test showed that the nurses gained significant knowledge on definition of the colostomy after the in-service education session. Question no. 2 regarding types of colostomy in pre-test the mean score was $0.46 \pm 0.94$ findings are similar to a study conducted at Assuit University Hospital, Egypt reporting that only 9.6\% of the nurses had true understanding about types of the colostomy (Bhzeh, et al., 2013). Whereas of the same question in post-test mean score was $4.59 \pm 1.35$, P-value $<0.05$. Paired 't' test found the significant enhancement of nurses knowledge about types of colostomy after attending the in-service session. Question no. 3 about the teaching needs of the colostomy patients the mean score in pre-test was $1.36 \pm 1.22$. While the same question in post-test mean score was $4.15 \pm 1.51$, P-value $<0.05$, Paired ' $t$ ' test proved the significant increase in nurses knowledge about the teaching needs of the colostomy patients after receiving the in-service education. Question no. 4 in pre-test regarding the food that should be recommended to colostomy patients showed the mean score of $0.23 \pm 0.49$ and the same question repeated in post-test showed the significant difference in mean score 4.44 \pm 1.37 , P-value $<0.05$. Paired' $t$ ' test observed that the nurses gained noteworthy knowledge about the food that should be recommended to colostomy patients after the intervention of in-service education. The last item question no. 5 in pre-test that was about listing the supplies and 3 competencies required for colostomy care the mean score was $1.74 \pm 1.76$ and in post-test same repeated question illustrated mean score $4.51 \pm 1.17$ and $p$-value $<0.05$, Paired ' $t$ ' test established the significant improvement in nurses knowledge regarding colostomy care after attending the in-service session.

Data was further analyzed and found, that overall pre-test and post-test statistically showed significant difference in the knowledge score obtained by the study participants. The overall pre-test mean score came out to be $6.08 \pm 3.74$ showing that the majority of study participants had poor and average knowledge about the colostomy care. These findings are similar to recent study (Lebona, et al., 2016). Previous literature also reported unsatisfactory level of nurses knowledge regarding colostomy care pointing out that nurses were unable to provide quality nursing care to colostomy patients due to lack of required information related colostomy care. This deficiency in nurses knowledge may be due to lack of information and set standard for colostomy care (Bhzeh, et al., 2013). Present study also presume that study participants coming from different parts of the country 
Texila International Journal of Clinical Research

Volume 3, Issue 2, Dec 2016

with different background of schooling and work experience carrying from low standard organizations and joining the study hospital are deprived from on-job/continue education opportunities. These nurses should be given the top priority to assess their learning need specifically related to colostomy care and provided with in-service education sessions.

Overall post-test showed mean score of $22.38 \pm 5.54$ establishing that the majority of the study participants ( $n=34,87.18 \%)$ had excellent level of knowledge about colostomy care after the inservice education session. Paired't' test revealed that nurses had significant knowledge gain after the in-service education session. P-value $<0.05$, the null hypothesis (H0) rejected at the $95 \%$ confidence interval (CI). Similar findings were found in the literature showing the significant difference between pre-test and post-test scores on nurses knowledge for ostomy care (Bales, 2010).

Many studies suggested to keep the nurses knowledge and skills up dated to help the colostomy patients (Ardigo \& Amante, 2013; Bulkley et al., 2013; Dabirian, et al., 2011; Gül, et al., 2013; Sun et al., 2014). Nurses should be equipped with necessary knowledge and skills to help the colostomy patients. A specialized ostomy nurses are needed for ostomy management and minimizing the complications related to stoma (Zakri, et al., 2010).

This study results corresponds to recent literature that nurses who are up-dated with current knowledge and skills related to colostomy care are in better position to provide comfort to the patients who live with colostomy (Ardigo \& Amante, 2013; Bhzeh, et al., 2013; Bulkley, et al., 2013; Recalla, et al., 2013; Zakri, et al., 2010). Comfort concept is very much important in hospital setting where sick people come to seek comfort in general and colostomy care specifically. Nurses has primary responsibility to assess and listen to the colostomy patients carefully to understand their problem and plan appropriate interventions to relief their pain and worries without wasting time. Nurses are responsible to own the colostomy patients and look after their comfort level: physical, psychological, social and spiritual needs on time as expected by the individuals.

At the end of the in-service education session the study participants verbalized that, they feel happy and empowered with the gained knowledge to practice colostomy care. Nurses showed high confidence and dedication to apply the learnt knowledge at work place. Further, they were eager to learn more about the colostomy care. This indicated that colostomy care in-service education should be on going for nurses to keep them updated with warranted knowledge and skills for colostomy care. The author believes that in-service education sessions for nurses are always highly beneficial for their professional practice, delighted patients and improving the image of the organization in which they work. It is prime important for nurse managers to assess/reassess this essential aspect of nurse's knowledge time to time, so, they may be provided with in-service education/workshops/seminars on regular basis.

\section{Limitations}

Limitations of the current study were small sample size and short tool for data collection. Although this study plan limits the generalization of the findings, the information provided supports the need for further research on a larger sample of the nurses caring for colostomy patients. A much larger study sample will validate the reliability and confirming the findings of this study.

\section{Conclusion}

In conclusion, the pre-test statistically established that the study participants were deficient of knowledge regarding colostomy care. However, the post-test statistically proved that structured education program was highly effective to improve the knowledge towards colostomy care among the nurses working in male and female surgical units showing significant difference in pre-test and posttest scores. At the end of the session the study participants verbalized that, they feel happy and empowered with the gained knowledge to practice colostomy care. They also showed high interest to learn more about the topic. Therefore, it is prime important for nurse managers to assess/reassess this essential aspect of nurse's knowledge so, nurses may be provided with in-service education/workshops/seminars on regular basis. 
Although the sample size was small and study findings cannot be generalized even then study has the implication on nursing practice, education, administration and research.

Further, interventional/experimental research is warranted on larger sample to verify the findings of this study.

\section{Implication of the study \\ Clinical nursing practice}

The study aimed to assess the nurse's knowledge and indicate the need for required knowledge regarding colostomy care. The study will motivate the nurses to provide quality care to the colostomy patients. Moreover, the study will indicate the nurses need for specialized colostomy care modular education requirement. The study will help in reducing the length of hospital stay and cost of the treatment in colostomy patients. Colostomy increases the risk of infection of the surrounding skin and infection of stoma, malnutrition, non compliance of the treatment, complications of the stoma that are stoma retraction, prolapsed, hernia and other psychological problems in patients. Further, colostomy leads to poor quality of life so this research will build up foundation to improve the quality of life of the patients with lifelong colostomy. Recent literature suggest that every organization and profession must set standards of care to guide their workers to deliver best possible care (Bhzeh, et al., 2013).

\section{Nursing education}

The educational needs of colostomy patients are diverse. Nurses need to learn more about preparing the patients for self-care and living and managing with colostomy. Nurses must educate the patients and family members (caregiver) that the risk of infection of the surrounding skin and infection of stoma, malnutrition, complications of the stoma (stoma retraction, prolapsed, hernia), psychological problems and non compliance of treatment can prolong the hospital stay and treatment cost. Patient and family teaching like the need of frequent colostomy care reduce the side effects and complications of colostomy and ultimately the cost of treatment. The nurse educators may use the study findings as useful information for the students. Nursing education should instill the values and sense of accountability in the students to educate the colostomy patient and caregiver for comfortable living with colostomy.

\section{Nursing administration}

The nurse administrator can make use of these study findings to encourage the nurses to practice evidence-based practice and transfer the knowledge among the student nurses. In addition, seminars and workshop can be organized to strengthen the base of knowledge related to colostomy care. The nurse administrators can promote further research on same topic to develop body of knowledge for generalization of the findings and diverse aspects of the research for further inquiry into the problem. The findings of the study should be used as a basis of in-service education programs for nurses so their knowledge regarding colostomy care may be enhanced.

\section{Nursing research}

There is limited research work done on nurse's knowledge regarding colostomy care. The research findings and research design may be used as avenues in future researches for generalization. Nurses working with colostomy patients on bedside should be actively involved in research activities to generate evidence-based knowledge with the support of senior nurses/managers.

\section{Acknowledgement}

My exceptional thanks to Ghuncha Samee Nurse Manager to identify the nurses training need and involve Nursing Education Services Department to facilitate in-service session for nurse's professional development. 
Texila International Journal of Clinical Research

Volume 3, Issue 2, Dec 2016

My special thanks to Nazish Kashif Clinical instructor to assist the training session from start to end.

I am also thankful to Adnan Zafar office coordinator for his technical support in computer applications and data analysis.

\section{References}

[1]. Anaraki, F., Vafaie, M., Behboo, R., Maghsoodi, N., Esmaeilpour, S., \& Safaee, A. (2012). Quality of life outcomes in patients living with stoma. Indian Journal of Palliative Care, 18(3), 176-180. doi: 10.4103/09731075.105687

[2]. Ardigo, F. S., \& Amante, L. N. (2013). Knowledge of the Professional about Nursing Care of People With ostomies and their Families. Text Context Nursing, 22(4), 1064-1071. doi: https://dx.doi.org/10.1590/S010407072013000400024

[3]. Baldwin, C. M., Grant, M., Wendel, C., Hornbrook, M. C., Herrinton, L. J., McMullen, C., \& Krouse, R. S. (2009). Gender differences in sleep disruption and fatigue on quality of life among persons with ostomies. J Clin Sleep Med, 5(4), 335-343.

[4]. Bales, I. (2010). Testing a computer-based ostomy care training resource for staff nurses. Ostomy Wound Manage, 56(5), 60-69.

[5]. Bhzeh, N. M., Teleb, S. M., Mahmoud, M. A., \& Soliman, A. M. (2013). Colostomy: Developing Nursing Care Standards for Patient with Colostomy. The Medical Journal of Cairo University, 81(2), 57-64.

[6]. Bulkley, J., McMullen, C. K., Hornbrook, M. C., Grant, M., Altschuler, A., Wendel, C. S., \& Krouse, R. S. (2013). Spiritual well-being in long-term colorectal cancer survivors with ostomies. Psychooncology, 22(11), 2513-2521. doi: 10.1002/pon.3318

[7]. Burch, J. (2011). Resuming a normal life: holistic care of the person with an ostomy. British Journal of Community Nursing, 16(8), 366-373. doi: 10.12968/bjcn.2011.16.8.366

[8]. Dabirian, A., Yaghmaei, F., Rassouli, M., \& Tafreshi, M. Z. (2011). Quality of life in ostomy patients: a qualitative study. Patient preference and adherence, 5, 1-5. doi: 10.2147/ppa.s14508

[9]. Gül, P., Ayhan, A., \& Tevfik, P. (2013). Emotions of gynecologic cancer patients dealing with permanent colostomy: a qualitative interview study. Journal of Cancer Therapy, 4(6), 1060-1067. doi: http://dx.doi.org/10.4236/jct.2013.46120

[10]. Krans, B. (January 8, 2016). What is Colostomy Retrieved June 28, 2016, from http://www.healthline.com/health/colostomy\#Overview1

[11]. Krouse, R. S., Herrinton, L. J., Grant, M., Wendel, C. S., Green, S. B., Mohler, M. J., ... Hornbrook, M. C. (2009). Health-Related Quality of Life Among Long-Term Rectal Cancer Survivors With an Ostomy: Manifestations by Sex. Journal of Clinical Oncology, 27(28), 4664-4670. doi: doi:10.1200/JCO.2008.20.9502

[12]. Lebona, B., Jasmine, E., Lakshmi, K., \& Indira, D. (2016). Assess the knowledge regarding colostomy care among staff nurses and nursing students in $\mathrm{NMCH}$, Nellore International Journal of Applied Research, 2(5), 306-310.

[13]. Polit, D. F., \& Beck, C. T. (2004). Nursing research principles and methods (Seventh ed.). Philadelphia: Lippincott Williams \& Wilkins.

[14]. Recalla, S., English, K., Nazarali, R., Mayo, S., Miller, D., \& Gray, M. (2013). Ostomy care and management: a systematic review. Journal Wound Ostomy Continence Nurses, 40(5), 489-500; quiz E481-482. doi: 10.1097/WON.0b013e3182a219a1

[15]. Sinha, A., Goyal, H., Singh, S., \& Rana, S. P. (2009). Quality of life of ostomates with the selected factors in a selected hospital of delhi with a view to develop guidelines for the health professionals. Indian journal of palliative care, 15(2), 111-114. doi: 10.4103/0973-1075.58455

[16]. Smith, D. M., Loewenstein, G., Rozin, P., Sherriff, R. L., \& Ubel, P. A. (2007). Sensitivity to disgust, stigma, and adjustment to life with a colostomy. Journal of research in personality, 41(4), 787-803. doi: 10.1016/j.jrp.2006.09.006 
[17]. Sun, V., Grant, M., McMullen, C. K., Altschuler, A., Mohler, M. J., Hornbrook, M. C., ... Krouse, R. S. (2014). From diagnosis through survivorship: health-care experiences of colorectal cancer survivors with ostomies. Support Care Cancer, 22(6), 1563-1570. doi: 10.1007/s00520-014-2118-2

[18]. Thamilselvam, P., Khairuzi, S., \& Fadzli, I. (2013). Quality of life after colostomy. Reviews of Progress, 1(19), 1-4. doi: http://reviewsofprogress.org/UploadedArticle/37.pdf

[19]. Zakri, R. H., Shah, S. A., Khaliq, T., \& Asghar, T. (2010). Impact of Ostomy Surgery on Hospitalized Patients at a Tertiary Care Hospital in Pakistan. Ann. Pak. Inst. Med. Sci, 6(1), 36-39. 